Aus der Königliohen dermatologischen Univ.-Klinii in Breslau. (Direktor: Geheimrat Prof. Dr. N ei s s e r.)

(Serologische Abteilung: Prof. Dr. C. Bruck.)

\title{
Klinische und bakteriologisch-serologische Studien über Ulcus molle und Ducreysche Streptobazillen.
}

Von

Tetsuta Ito (Tokio).

Ich habe an der hiesigen Klinik verschiedene Versuche mit dem Erreger von Ulcus molle anstellen können und möchte im folgenden die Resultate meiner klinischen und bakteriologisch-serologischen Beobachtungen wiedergeben.

\section{Klinische Versuche.}

1. Kutane Reaktion mit Streptobazillen-Emulsion.

2. Behandlung von Ulcus-molle-Bubonen mit Streptobazillen-Emulsion.

3. Über die Ursacheder Babonen bei Ulcus molle.

\section{Bakteriologisch-serologische Versuche.}

1. Über die Kultur der Streptobazillen unter besonderer Berücksichtigung meiner neuen Nährböden.

2. Über das Streptobazillengift.

3. Über Immunität und Anaphylaxie durch Streptobazillen.

4. Präzipitations-, Agglutinations- und Komplementbindungsversuche mit Streptobazillen. 


\section{Klinische Versuche.}

\section{Kutane Reaktion mit Streptobazillen-Emulsion.}

Die durch die Ducreyschen Bazillen verursachten Affektionen kommen sehr häufig zur Untersuchung und es ist oft sehr notwendig, sie von anderen venerischen L.eiden zu unterscheiden. Insofern dürfte es nicht ohne Interesse sein, ein biologisches Hilfsmittel für klinisch-diagnostische Zwecke bei diesen Leiden zu besitzen.

Nach den mühsamen Arbeiten vieler Autoren steht es heute fest, daß die Bubonen bei Ulcus molle - abgesehen von seltener Mischinfektion durch Eindringen der Streptobazillen in die regionären Lymphdrüsen entstehen können. Vergleicht man aber die Spärlichkeit der in Bubonen nachzuweisenden Bazillen mit den von den erkrankten Drüsen ausgehenden sehr heftigen Entzündungserscheinungen und andererseits die relativ geringen entzündlichen Reaktionen, die von den massenhaften Streptobazillen im Ulcus inolle selbst hervorgerufen werden, so kann der Gedanke nicht unterdrückt werden, daß der Symptomkomplex der reinen - also nicht durch Mischinfektionen erzeugten - Ulcus molle Bubonen nicht nur rein pathologisch-anatomisch erklärt werden kann, sondern vielleicht mit einer im Körper durch die Ulcus molle-Infektion gesetzten gesteigerten Reaktionsfähigkeit gegenüber den Streptobazillen zusammenhängt.

Auf Grund dieser Vermutung stellte ich folgende Tierexperimente an:

Ich habe normale gesunde Kaninchen in Intervallen von zirka 5 Tagen mit einer abgetöteten Emulsion von Streptobazillen dreimal vorbehandelt und habe den so behandelten Kaninchen zirka 2 Wochen nach der letzten Injektion wieder eine kleine Menge derselben Emulsion intrakutan in die Haut des Hodensackes injiziert. Dabei zeigte sich folgendes: Es trat am nächsten Tage eine über markstückgroße entzündliche Reaktion an der Injektionsstelle auf, während sie in demselben Versuche bei dem nicht behandelten Kontrolltiere ausblieb. Nach diesem interessanten Ergebnis, das also für die Möglich- 
keit einer spezifischen Streptobazillen-Cutireaktion sprach, habe ich an einer größeren Anzahl von Patienten Versuche angestellt, um diese Tatsache für klinisch-diagnostische Zwecke verwertbar zu machen.

Technik: Zur Darstellung der Streptobazillen-Emulsion wurden Streptobazillen-Kolonien, die auf 2 schrägen Kaninchenblutagarröhrchen nach 24 Stunden bei $37^{\circ}$ üppig gewachsen waren, in $1 \mathrm{ccm}$ physiologischer Kochsalzlösung fein emulgiert. Um Fäulnis z:u vermeiden, wurde $0.5 \%$ reine Karbolsäure hinzugefügt und diese Emulsion bei $60^{\circ}$ im Wasserbad zwei Stunden lang erhiżt, um die lebenden Streptobazillen abzutöten. Es wurde sodann auf Sterilität der Emulsion geprüft. Ich nenne im folgenden diese Emulsion StreptobazillenVakzin.

Einige Tropfen dieses Vakzins wurden intrakutan am Oberarm der Kranken mittels Pravazscher Spritze injiziert, nachdem vorher die Haut mit Alkohol oder Benzin gereinigt worden war. Es wurde eine möglichst feine Nadel zur Injektion verwendet, um eine stärkere mechanische Reizung der Kutis zn vermeiden.

Die analog der Pirquetsehen Tuberkulinreaktion angestellten kutanen Impfungen ergaben nur sehr schwache reaktive Entzündungen, so daß mir diese Methode für meine Versuche nicht geeignet erschien.

Nach intrakutanen Kutireaktionen mit Streptobazillenvakzin bei Leuten, die noch keine StreptobazillenInfektion durchgemacht hatten, sind die entzündlichen Erscheinungen, die an der Injektionsstelle auftreten, im allgemeinen nur sehr gering, und zwar entsteht am Tage nach der Injektion entweder überhaupt keine Reaktion oder nur ein leichtes Erythem, das ungefähr erbsengroß, leicht gerötet, vom umgebenden Hautniveau etwas erhaben, nicht induriert ist und keinerlei subjektive Beschwerden verursacht. Dieses Erythem bleibt zwei bis höchstens drei Tage an der Injektionsstelle bestehen. (Diesen Grad der Kutireaktion bezeichne ich als negative Reaktion.)

Dagegen ist dieKutireaktion bei Ulcus molle, besonders aber beiBubokranken stets sehr stark, 
so daß man sie sehr leicht von einer "negativen Reaktion" unterscheiden kann. Es handelt sich stets um sehr stark gerötete, scharf umgrenzte, nicht selten bis zur doppelten Größe eines Fünfmarkstückes ausgedehnte, ödematös angeschwollene $Q u$ addel $n$, die im Zentrum, d. h. an der Einstichstelle, am stärksten hervortreten und meist deutlich starke Induration zeigen, so daß man sofort an das Bild des Erysipels erinnert wird. Außerdem beobachtete ich noch Reaktionen, die 24 Stunden nach der Injektion folgendes Bild zeigten: An der Injektionsstelle fand sich eine über zehnpfennigstückgroße, stark gerötete und angeschwollene zentrale Partie, die sehr stark induriert war. Dieser zentrale Teil war umgeben von einem scharf begrenzten erythematösen Hof, der nach einigen Tagen verschwand, während der zentrale Teil etwa über 10 Tage bestehen blieb.

Neben der Quaddelbildung kommt es mitunter aisch zu einer akuten Lymphangitis und Lymphadenitis der regionären Drïsen. Bei Bubokranken entsteht meistens innerhalb 48 Stunden, oft schon nach 24 Stunden, eine erbsengroße AbzeBbildung im Zentrum, die allmählich spontan resorbiert wird. Die Reaktion erreicht in 24 bis 48 Stunden nach der Vakzininjektion die Akme ihrer Entwicklung und geht allmählich binnen zehn Tagen zurück.

Diese Kutireaktion ist nun bei Streptobazilleninfektion umso deutlicher, je stärker die pathologischen Veränderungen des Krankbeitsherdes sind.

Neben der lokalen Reaktion an der Injektionsstelle treten bisweilen auch Allgemeinerscheinungen auf, wie Temperatursteigerungen, die am ersten oder zweiten Tage nach der Injektion eine Höhe von $375^{\circ}$ erreichen, außerdem selten leichter Kopfschmerz, der verhältnismäßig rasch vorübergeht. Diesen starken Grad der Kutireaktion nenne ich "positive Reaktion".

Meine Resultate sind folgende: Bei $11 \mathrm{Kranken}$, die von Ulcus molle oder Bubonen frei sind, sind die Kutireaktion sämtlich negativ ausgefallen. Bei zwei Fällen trat aber die erythematöse Reaktion 
etwas größer als ein Zehnpfennigstück auf, jedoch von keiner Induration, AbszeBbildung oder irgend welchen subjektiven Beschwerden begleitet; die Reaktion ging schon in drei Tagen spurlos zurück.

Unter fünf Ulcus molle-Kranken waren drei Fälle stark positiv, $z w e i$ andere reagierten mäBig stark. Als einen nicht geklärten Fall möchte ich folgenden erwähnen: Es handelt sich um eine Wöchnerin, die mit der Diagnose "Syphilis latens" aufgenommen worden war, da sie mehrere Monate vor ihrer Aufnahme einen ulzerösen Prozeß an den Genitalien gehabt hatte und zurzeit das Geschwür geheilt war. Die Kutireaktion fiel mäßig stark aus. Ob damals neben dem syphilitischen Prozeß auch noch Ulcera mollia bestanden habe, konnte mit Sicherheit nicht festgestellt werden.

Bei 11 Kranken, die an Ulcus molle und gleichzeitig Bubonen litten, war die Reaktion stark positiv, und zwar traten fast immer Abszeßbildungen an den Injektionsstellen auf, wohingegen, wie beschrieben, nie Abszeßbildungen bei den als Kontrolle dienenden Patienten, welche bisher keine Streptobazillen-Infektion durchgemacht hatten, beobachtet wurde. Es entsteht also bei Bubokranken eine Abszeßbildung, nicht nur durch lebende, sondern auch durch abgetötete Streptobazillen.

Nach meinen Versuchen ist die Kutireaktion mit Streptobazillen-Vakzin für die durch Streptobazillen verursachen Krankheiten spezifisch und eventuell ein Hilfsmittel zur Sicherung der klinischen Diagnose.

\section{Wie ist nun diese Kutireaktion zu erklären?}

Es liegt nahe, daran zu denken, daß diese spezifische Reaktion wie die Kutireaktion bei Tuberkulose eine Überempfindlichkeitserscheinung ist.

Um diese Ansicht zu bestätigen, habe ich bei einem Kollegen, der nicht an Ulcus molle litt oder gelitten hatte 
und bei dem die erste Kutireaktion mit Streptobazillenvakzin sehr schwach war, Streptobazillenvakzin in steigenden Dosen dreimal injiziert und habe zehn Tage nach der letzten Injektion wieder die Kutireaktion geprüft. Fs entstand ein über fünfmarkstückgroßer, stark geröteter, angeschwollener, hart indurierter und beim Betasten schmerzhafter Herd, der am nächsten Tage eine erbsengroße Abszeßbildung an der Injektionsstelle aufwies. Diese starke Reaktion ging nach 10 Tagen ohne eine lokale Behandlung rollständig zurück.

Dieser Versuch zeigt, daß auch eine Vakzinbehandlung keinen neutralisierenden Einfluß auf das Antigen ausübt, sondern im Gegenteil, dab wahrscheinlich eine derartige biologische Veränderung im Organismus entsteht, die bei einer wiederholten Einführung des Antigens einen stärkeren Ausfall der Reaktion bewirkt, d. h. daß der betreffende Organismus nach der Antigenzufuhr in einen anaphylaktischen Zustand kommt. Nach Friedberger entsteht der anaphylaktische Antikörper im Organismus nach der Antigenzufuhr, die in diesem Falle in den Streptobazillen besteht, welche lebend oder abgetötet in gleicher Weise wirken. Dieser Antikörper verbindet sich mit dem zum zweiten Male eingeführten Antigen und diese Verbindung = Anaphylatoxin (Friedberger) ist für den Organismus giftig und erzeugt die lokale reaktive Entzündung i. e. positive Kutireaktion.

Was die Tatsache betrifft, daß bei den Kontrollfällen nach Vakzineeinfuhr häufig eine leichte entzündliche Reaktion auftritt, so kann man diese, wenn man nicht die unspezifische Reizwirkung der injizierten Emulsion als genügende Erklärung ansehen will, vielleicht noch dadurch erklären, daß der norm.al vorhandene Antikörper oder der nach der Vakzineeinfuhr in den Organismus binnen mehreren Stunden sich bildende Antikörper mit dem eingeführten Antigen sich bindet und daß dann die kleine Menge des entstehenden Anaphylatoxin die relativ leichtere Kutireaktion auch bei nicht infizierten Organismen hervorbringt.

Die Stärke der Kutireaktion mit Streptobazillenvakzin ist selbstverständlich von der Menge des Anaphylatoxins 
abhängig, und das Anaphylatoxin ist die Ursache nicht nur der Hautentzündung, sondern auch der Abszeßbildung des Gewebes. Es ist auch wahrscheinlich, daß der anaphylaktische Antikörper gegen Streptobazillenvakzin bei Bubokranken in größerer Menge als bei Ulcus molle-Kranken vorhanden ist, da die Kutireaktion bei Bubokranken fast immer stärker als die der Ulcus molle-Kranken ist. (Siehe auch Versuch 8.)

Klinisch scheinen mir die Versuche dafür zu sprechen, daß bei der Bubonenentstehung im Lanfe der Ulcus molleinfektion außer der einfach Entzïndung erzeugenden Wirkung des Erregers in den Lymphdrüsen, dieser von mir nachgewiesene sich durch die Infektion entwickelnde anaphylaktische Zustand eine wesentliche Rolle spielt.

\section{Behandlung der durch Ducreysche Streptobazillen erzeugten Bubonen.}

Die bei dem thcus molle meist einige Wochen nach der Infektion auftretenden Bubonen (in ungefähr $30 \%$ aller Fälle) sind für den Patienten eine unangenehme Komplikation, die den Kranken weit mehr belästigen als der weiche Schanker selbst und wenn auch die verschiedensten Behandlungsmethoden für Bubonen angegeben wurden, so gibt es doch heutzutage keine, die wirklich ganz befriedigende Resultate lieferte.

Meine Versuchsresultate, die bei Bubokranken die Kutireaktion deutlich stärker zeigten, als bei Ulcus molle-Erkrankten, sowie die Ansicht, die ich eben angeführt habe, daß bis zu einem gewissen Grade der Bubo eventuell den Ausdruck einer anaphylaktischen Unstimmung des Organismus darstellt, ließe die Frage interessant erscheinen, ob es gelingt, Bubonen mit Streptobazillenvakzin kausal zu behandeln.

Ich habe mit Streptobazillenvakzin zwölf Bubokranke behandelt und dabei gute Resultate bekommen, so daß ich den Eindruck habe, daß diese spezifische Behandlung den üblichen Methoden überlegen ist.

Einige Fälle möchte ich hier in Kürze referieren.

Technik: Als Streptobazillenvakzin habe ich die gleiche Emulsion, die bei der Kutireaktion schon beschrieben wurde, verwendet und habe 
immer intramuskulär für den Erwachsenen 0.5 bis $0.7 \mathrm{~cm}$ als erstmalige Injektion gebraucht, bei einer zweiten Injektion wendete ich eine höhere Dosis an.

Fall 1. Olz., 25 Jahre alt, Schmied, am 3./X. in die Klinik aufgenommen.

Anamnese: Infektion etwa Mitte Angust 1912, 8 Wochen später Geschwür am Sulcus coronarius penis. Seit mehreren Tagen schmerzhafte Anschwellung in der rechten Inguinalgegend.

Status: Ein erbsengroßes Geschwür am Sulcus coronarius penis. Sehr schmerzhafte, über walnußgroß angeschwollene Lymphdrüse in der rechten Inguinalgegend, die Haut darüber stark dunkel lividrötlieh verfärbt, die angeschwollenen Lymphdrüsen mit der Haut und deren Unterlage verwachsen; keine Fluktuation.

Diagn os e: Uleus molle im Sulens coronarius penis, dolenter Bubo inguinalis dextr.

Behandlung mit Streptobazillenvakzin und Verlauf:

9./X. Vakzin 0.7 ccm intramuskulär in die Glutäalgegend injiziert; keine lokale Behandlung des Bubo.

10./X. Schmerzen am Bubo dentlich vermindert, so daß nur der Fingerdruck leicht schmerzhaft war. Temperatur $37 \cdot 7^{\circ}$.

11./X. Bubo schmerzt nicht mehr, gerötete Haut deutlich abgeblaßt.

12./X. Bubo verkleinert.

14./X. Bubo weit mehr verkleinert, hart, schmerzfrei. Hautrötung fast verschwunden. Ulcus molle noch nicht geheilt.

Heildaner des Bubo zirka 5 Tage.

Fall 2. I. D., 23 Jahre alt, Schiffer, am 27./X in die Klinik aufgenommen.

Anamnese: Gegen Mitte Oktober 1912 Geschwüre an der Vorhaut des Penis, seit etwa 20./X. schmerzhafte Anschwellungen in beiden Inguinalgegenden.

Status: Drei linsengroße Geschwüre am Präputium, sehr schmerzhafte, über walnußgroße Bubonen in beiden Inguinalgegenden, die mit stark geröteter Haut bedeckt und auf der Unterlage nicht verschiebbar sind. Keine Fluktuation.

Diagnose: Ulcera mollia am Präputium des Penis, dolente Bubonen beiderseits.

Behandlung mit Streptobazillenvakzin und Verlauf:

28./X. Streptobazillenvakzin 0.7 ccm intramuskulär in die Glatäalgegend injiziert. Keine lokale Behandlung des Bubo.

29./X. Rötung der Haut über den Bubonen deutlich abgeblalit. Temperatur $39^{\circ} 5^{\circ}$, leichter Kopfschmerz und Mattigkeit. Bubonen nicht mehr schmerzhaft.

30./X. Deutlicher Rückgang der Bubonen, Geschwüre an der Vorhant abgeflacht ohne lokale Behandlung.

31./X. Linker Bubo deutlich verkleinert, kein Schmerz; rechter Bubo wieder leicht schmerzhaft. 
1./XI. Rechter Bubo wieder stärker geschwollen, Haut leicht gerötet, Schmerzen nehmen zu; linker Bubo fast geheilt.

2./XI. Geschwüre am Penis bis auf einen kleinen Rest überhäutet. 2. Injektion von Streptobazillenvakzin $1.0 \mathrm{ccm}$ in die Glutäalgegend.

3./XI. Schmerzen im rechten Bubo nur noch in geringem Grade.

4./XI. Rechter Bubo schmerzt nicht mebr, deutlich verkleinert, die gerötete Hant abgeblaßt.

5./XI. Keine Beschwerden mehr, geheilt.

Heildaver 1. Bubo zirka 4 Tage, r. Bubo zirka 8 Tage.

Fall 3. Wk., 35 Jahre alt, Mechaniker, am 16./XI. in die Klinik aufgenommen.

Anamnese: Vor 4 Wochen Infektion, vor 3 Wochen-Geschwür am Sulcus coronarius penis, seit 8 Tagen schmerzhafte Anschwellung an der rechten Inguinalgegend.

Status: 3 Geschwüre im Sulcus coronarius penis, stark schmerzhafter, über walnußgroßer Bubo in der rechten Inguinalgegend mit intensiv geröteter Haut bedeckt, die auf ihrer. Unterlage nicht verschieblich ist. Keine Fluktuation, Temperatur $38^{\circ}$.

Diagnose: Ulcera mollia im Sulcus coronarius penis. Dolenter Bubo inguinalis dextr.

Behandlung 'mit Streptobazillenvakzin und Verlauf:

17./XI. Die entzündlichen Erscheinungen des Bubo nehmen trotz lokaler feuchter Umschläge und absoluter Bettruhe zu.

18./XI. Streptobazillenvakzin $0.7 \mathrm{cem}$ intramuskulär in die Glutäalgegend injiziert.

19./XI. Schmerz im Bubo fast verschwunden, Rötung besteht noch, leichter Kopfschmerz, Temperatur $375^{\circ}$.

20./XI. Keine Schmerzen im Bubo, Rötung der Haut verblaßt, Bubo selbst deutlich verkleinert.

21./XI. Bubn wesentlich kleiner.

23./XI. Drüsenschwellung verkleinert, fast wie auf der gosunden Seite, die Geschwüre bestehen noch, sind aber durch Karbolsäureätzung und Jodoformpuder deutlich gebessert.

Heildauer des Bubo zirkà 5 Tage.

Fall 4. K. J., 25 Jahre alter Arbeiter, poliklinisch behandelt.

Anamnese: 20./X. 3 Geschwüre im Sulcus coronarius penis.

24./X. Schmerzhafte Anschwellung in der linken Inguinalgegend.

Status: Vier ungefähr erbsengroße Geschwüre' im Sulcus coronarius penis. Linke Inguinaldrüse über walnußgroß angeschwollen, die darüberliegende Haut sowie auf der Unterlage nicht verschiebbar; die Haut intensiv dunkelrot verfärbt, keine Fluktuation nachweisbar.

Diagnose: Ulcera mollia im Sulc. coron. penis. Dolenter Bubo inguinalis sinistr.

Behandlung mit Streptobazillenvakzin und Verlauf: 
26./X. Streptobazillenvakzin $0.7 \mathrm{ccm}$ intramuskulär injiziert, keine lokale Behandlung des Bubo. Ulcera mollia mit reiner Karbolsäure geätzt und mit Jodoform gepudert.

27./X. Schmerzen im Bubo fast geschwunden. Die Hautrötung hat dentlich zugenommen. Bubo zentral erweicht in etwa Fingerspitzgröße. Deutliche Fluktuation.

28./X. Keine Schmerzen mehr im Bubo, Hautrötung deutlich verblaßt, Fluktuation noch nachweisbar.

31./X. Die Rötung des Bubo ist fast geschwunden. Bubo selbst deutlich verkleinert, keine Fluktuation mehr nachweisbar. Ulcera mollia bestehen noch trotz Karbol- und Jodoformbehandlung.

2. XI. Bubo abermals verkleinert, hart, die Hautrötung vollkommen verschwunden, die vier Geschwüre bestehen noch.

Heildauer des Bubo zirka 7 Tage.

Fall 5. Ott., 25 Jahre alter Schiffer. 31./X. in die Klinik aufgenommen.

A n a m nese: Zeit der Infektion nicht zu ermitteln. 10./X. Geschwür am Penis. 28./X. Schmerzhafte Anschwellung in der linken Inguinalgegend.

Status: Geschwür am Penis abgeheilt. Bubo in der linken Inguinalgegend über walnußgroß, zeigt deutliche Fluktuation, die Haut darüber dunkelrot verfärbt, sehr dünn, bei Fingerdruck leicht schmerzhaft.

Diagnose: Dolenter Bubo inguinalis purulenta sinistr.

Behandlung mit Streptobazillenvakzin und Verlauf:

31./X. Kleine Stichinzision des Bubo. Jodoformvaselininjektion.

1./XI. Die Hautrötung ist noch sehr stark, Bubo bei Fingerdruck leicht schmerzhaft. Streptobazillenvakzin $0.7 \mathrm{ccm}$ in die Glutäalgegend injiziert.

2./XI. Keine Schmerzen im Bubo bei Fingerdruck, die Rötung deutlich abgeblaßt. Temperatur $37 \cdot 5^{\circ}$.

4./XI. Bubo deutlich verkleinert, die Hautrötung deutlich abgeblaBt. 7./X. Geheilt und entlassen.

Heildauer des Bubo zirka 7 Tage.

Weitere sieben Bubofälle, die mit Streptobazillenvakzin behandeltwurden, verliefenebenso gut, wie in den oben angeführten Fällen. Ihre Heildauer betrug ungefähr eine Woche.

Ich möchte im folgenden etwas ausfülrlicher auf die Wirkung des Streptobazillenrakzins auf die einzelnen Symptome des Bubo eingehen:

1. Der Schmerz der Bubonen läßt schon mehrere Stunden nach der Streptobazillenvakzininjektion nach und verschwindet meist einen Tag nach der Vakzininjektion, spätestens aber am zweiten Tage. 
2. Die entzündliche Rötung der Haut, die den Bubo bedeckt, fängt schon 24 Stunden nach der Vakzininjektion an abzublassen und man sieht meist am zweiten Tage eine deutliche Abnahme der entzündlichen Rötung, die dann je nach dem Grade der Entzündung einige oder mehrere Tage später vollkommen verschwindet.

Bei Fall 4 beobachtete ich, daß die Rötung des Bubo am Tage nach der Vakzininjektion deutlich zunahm, jedoch am dritten Tage anfing abzublassen und endlich nach 4 Tagen ganz geschwunden war. Diese Erscheinung kann vielleicht analog der Lokalreaktion bei Hauttuberkulosen nach einer Tuberkulinreaktion erklärt werden.

3. Was die Verkleinerung der Bubonen anbetrifft, so ging diese fast parallel mit der Abblassung der Hautrötung; zuerst nahm der Bubo an Umfang ab, dann wurde die Konsistenz härter, wozu es einige oder mehrere Tage bedurfte, je nach dem Grade der anfänglichen Schwellung, bzw. der pathologischen Veränderung der betreffenden Lymphdrüsen, schließlich kam es wieder zu normalen Verhältnissen.

Die Indikation für die Vakzinbehandlung ist in jedem Zustand der Bubonen nach Ulcus molle gegeben, wo entweder nur Schmerzen an den betreftenden entzündlichen Lymphdrüsen vorhanden sind, oder wo die Lymphdrüsen sehr stark angeschwollen sind, mit der geröteten Haut und ihrer Unterlage verwachsen sind, sogar in den Fällen, wo es bereits zu einer leichten Vereiterung gekommen ist.

Meist genügt eine Injektion, doch kann auch ausnahmsweise eine zweite Injektion nötig sein, wie auch bei einem meiner zwölf Bubofälle eine zweimalige Vakzininjektion notwendig war.

Die Heildauer bei der Vakzinbehandlung beträgt durchschnittlich eine Woche. Es ist natürlich selbstverständlich, daß die Wirkung um so sicherer und die Dauer der Heilung um so kürzer sein wird, je früher die Vakzinbehandlung einsetzen kann.

Als Nebenerscheinungen der Vakzinbehandlung kommen der lokale Schmerz an der Injektionsstelle und die Störungen des Allgemeinbefindens in Betracht, die viel- 
leicht als eine anaphylaktische Erscheinung nach der Antigeneinfuhr erklärt werden können.

a) Der Schmerz an der [njektionsstelle ist sehr verschieden, je nach der Reaktionsfähigkeit des Kranken und geht meistens binnen einiger Tage durch kalte Umschläge zurück. Um diese unangenehme Nebenerscheinung zu vermeiden, ist es wichtig, die Vakzininjektion nicht oberflächlich subkutan, sondern möglichst tief intramuskulär auszuführen.

b) Als Störung des Allgemeinbefindens zeigt sich zuerst eine Temperatursteigerung, die am Abend desselben oder am Tage nach der Vakzininjektion ihr Maximum erreicht und rasch vorübergehend ist. Das Fieber tritt nicht immer ein und ist ebenso wie der Schmerz an der Injektionsstelle verschieden. Die Temperaturen schwanken zwischen $37 \cdot 5^{\circ}$ und $39 \cdot 5^{\mathbf{0}}$. Außerdem klagen die Kranken oft über leichten Kopfschmerz und allgemeine Mattigkeit, die aber ebenfalls rasch vorübergehend sind.

Die Heildauer der mit den bisherigen Methoden. behandelten Bubonen ist im allgemeinen sehr verschieden. Doch heilen Bubonen von über Walnußgrößje, über denen die Haut stark gerötet ist, meist nicht unter einigen Wochen und nach einem chirurgischen Eingriff kaum vor einem Monat ab.

Dem gegenüber erscheint mir die Vakzinbehandlung der Bubonen in Anbetracht ihrer kurzen Heildauer als eine gute Methode, die auch für kosmetische $\mathrm{Z}_{\text {wecke sehr geeignet }}$ ist. Die Heilung der Bubonen kann aber sicherlich noch günstiger beeinflußt werden, wenn man die Vakzinbehandlung mit der üblichen lokalen Therapie (Umschläge etc.) kombiniert, was ich in meinen Versuchen absichtlich vermieden habe.

Veröffentlichungen von anderer Seite über Streptobazillenvakzinbehandlungen von Bubonen habe ich nicht finden können. Erwähnt sei nur eine Publikation meines japanischen Kollegen T. T'a mura in einer der letzten japanischen Zeitschriften für Dermatologie und Syphilis.

Auch nach seinen Angaben ist die Vakzinbehandlung eine gute und erfolgreiche Methode zur Behandlung der Bubonen. Das von ihm verwendete Vakzin besteht aus einer Emulsion von abgetöteten Strepto. bazillen, die auf Eigelb-Agar, Aszitesagar, Glyzerinagar, Bonillon und sogar einfachem Agar-Agar üppig wuchsen. Jedoch nach meinen Erfahrungen, ebenso wie nach den Angaben vieler Autoren (Lenglet, 
Besancon, Criffon, Le Sourd, Babes, Tomaszewski, F. Fischer, Lipschütz und Stein) wachsen die Streptobazillen, die Erreger des Ulcus molle, nicht auf einfachem Agar-Agar, Aszitesagar nnd Bouillon, und so glaube ich, daß das Vakzin Tamuras von dem von mir dargestellten Streptobazillenvakzin verschieden ist und nicht mit meinen Versuchen in Einklang zu bringen ist.

Was die Wirkung des Vakzins auf die Ulcera mollia selbst anbetrifft, so scheint mir die Heilung der Ulzera durch Vakzininjektionen we nig beeinflußt zu werden, da ich in meinen Versuchen nur zweimal die Geschwüre ohne Zuhilfenahme einer lokalen Behandlung abheilen sah. Dies widerspricht den Angaben N. Nakanos und Takemotos, welche bei der Vakzinbehandlung einen guten Einfluß auch auf die Heilung der Ulcera mollia gesehen haben. Über die Natur der von ihnen verwendeten Streptobazillen fehlen in ihrer Arbeit genauere Angaben.

Neben meiner Vakzinbehandlung habe ich bei Ulcus molle-Kranken lokal eine mit Streptobazillen dargestellte Sal be verwendet: Streptobazillen-Emulsion, und zwar in der doppelten Menge, wie sie für die Kutireaktion gebraucht wurde, $5 \cdot 0$, Vaselin $20^{\circ} 0$.

Nach meinen Erfahrungen scheint mir die Streptobazillensalbe ebenfalls keine Rolle bei der Heilung des Ulcus molle zu spielen.

Nach Angabe von R. H. Herbst (1912) lieferte die Behandlung mit Streptobazillensalbe gute Erfolge, doch waren die von ihm aus den Ulzera gezüchteten Bakterien-Pseudodiphtheriebazillen, die mit Streptobazillen vermischt waren. Nach seinen Angaben erscheint es mir zweifelhaft, ob seine sogenannte Streptobazillensalbe überha u t Ducreysche Streptobazillen enthalten hat.

Wie wirkt die Streptobazillenvakzineauf die Bubonen?

Wenn eine gesteigerte Bakteriolyse oder Phagozytose im Organismus nach der Vakzineinfuhr zustande käme und diese den Verlauf der Bubonen begünstigen würde, so müßte dieselbe auch wenigstens irgend einen guten Einfluß auf die Ulcera mollia ausüben, wo doch Streptobazillen reichlich vorhanden sind. Das ist jedoch nach meinen Versuchen nicht nachweisbar, obgleich das Streptobazillenvakzin auf die Bubonen sehr gut 
wirkt. Vermutlich spielt aber die Phagozytose nach der Vakzininjektion auch für die Heilung der Bubonen keine große Rolle.

Was die Frage einer eventuellen Immunität bzw. aktiven Immunität des Organismus anbetrifft, so möchte ich an dieser Stelle nur kurz erwähnen, daB der Körper nach der Vakzininjektion keine Immunität aufweist, welche imstande wäre, ein nachträglich eingeführtes Antigen (Streptobazillenvakzin) zu neutralisieren oder die Streptobazillen am Krankheitsherde in ihrem Wachtum zu stören oder abzutöten (cfr. nächstes Kapitel über Immunität).

Meines Erachtens spielt eine nach der Vakzininjektion entstehende Antianaphylaxie die Hauptrolle bei der Heilung des Bubo: nach dem Ausfall der Kutireaktion bei Bubokranken, der, wie ich gesagt habe, gegenüber der Reaktion bei unkomplizierten Ulcus molle-Fällen stets wesentlich stärker ist, müssen wir annehmen, daß sich der Körper des Bubokranken in einem anaphylaktischen Zustande befindet, mithin anaphylaktische Antikörper enthält. Führen wir nun dem Körper ein Antigen in Form von Streptobazillen zu, so kann man nach der Friedbergerschen Theorie annehmen, daß sich dieses Antigen mit dem im Körper vorhandenen anaphylaktischen Antikörpern unter Mitwirkung des Komplements zu Anaphylatoxin verbindet. Dadurch wird der anaphylaktische Antikörper gleichsam unwirksam und dies scheint mir die Ursache der Buboheilung zu sein.

\section{Öber die Ursache der Bubonen bei Ulcus molle.}

Nach den Angaben von vielen Autoren (Colombini, Bezancon, Griffon und Le Sourd, Lenglet, Lipschüz und Tomasczewski usw.) muß man annehmen, daf die Bubonen durch die eingedrungenen Streptobazillen in die regionären Lymphdrüsen bedingt sind.

Da das Streptobazillenvakzin auf die Buboheilung eine eklatante Wirkung ausübt, während es bei Ulcus molle fast gar keinen Einfluß hat, könnte man daraus schließen, daß auch die Ätiologie eines Bubo und eines Ulcus molle ver- 
schieden ist, und zwar so, daß vielleicht der Bubo nicht $\mathrm{n}$ ur durch die eingedrungenen Streptobazillen allein entsteht, sondern auch durch ein von innen abgegebenes Gift, welches aber nicht als einfaches Bakterientoxin wirkt, sondern sich eventuell mit dem Antikörper zu einem neuen Gift verbindet, das auf das Gewebe giftiger und schädlicher wirkt, als Streptobazillen allein oder mit deren Toxinen zusammen.

$\mathrm{Ob}$ der Bubo nur durch den mechanischen Reiz von den in die Lymphdrüsen eingedrungenen Streptobazillen oder die schädliche Wirkung deren Gifte bedingt wurde, weiß man nicht; vielleicht spielt das letztere die Hauptrolle dabei. Nach meinen Versuchen (das Nähere siehe nächstes Kapitel über das Streptobazillengift) ist das Gift der Streptobazillen nur ein Endotoxin (kein Exotoxin). Somit muß man annehmen, daß die Entstehung der Bubonen durch die Toxinwirkung nur insofern stattfinden kann, daß die in den betreffenden Lymphdrüsen massenhaft wachsenden Streptobazillen dort relativ rasch zu grunde gehen und daß das dadurch frei werdende Endotoxin die Entzündung verursacht.

Aus meinen Versuchen sieht man aber, daß das Vakzin, das Endotoxin der Streptobazillen, für den gesunden Organismus nicht so stark giftig wirkt als bei Bubokranken, bei denen nicht nur starke lokale Erscheinungèn, sondern auch allgemeine Störungen, und zwar anaphylaktische Erscheinungen auftreten. Streptobazillengift in kleinerer Menge verursacht keine starke Entzündung und keine Vereiterung; erst nach Verbindung des Antigen mit dem betreffenden Antikörper entsteht eine stärkere Giftigkeit (Anaphylatoxin). Es ist deswegen nicht fehlgehend, anzunehmen, $d a ß$ der Bubo bei Ulcus molle durch dieses neugebildete Gift, Anaphylatoxin entsteht. Um dies weiter zu bestätigen, möchte ich folgende Beweise anführen:

Die Heilung des Streptobazillenvakzins bei Bubonen, die weder die Folgeerscheinungen einer Immunität bzw. Antitoxinbildung : oder bakterizide Wirkung, noch einer gesteigerten Phagozytose des betreffenden Organismus ist, ist nach meiner oben dargelegten Auffassung, durch den antianaphylaktischen Zustand des Körpers, der nach der Antigeneinfuhr entsteht, 
zu erklären. Das eingeführte Antigen (Vakzin) verbindet sich mit dem betreffenden Antikörper, welcher im Verlaufe der Streptobazilleninfektion im betreffenden Organismus gebildet wird und eine sehr wichtige Komponente für die Entstehung der Bubonen sein dürfte. Infolge des Verschwindens des Antikörpers im betreffenden Organismus wird andererseits der Bubo zur schnellen Heilung kommen.

Ich nehme also an, daB der Bubo nicht nur durch die eingedrungenen Streptobazillen selbst, sondern durch das sogenannte Anaphylatoxin von Streptobazillen entstebt.

\section{Bakteriologisch-serologische Versuche.}

\section{Über die Kultur der Streptobazillen unter besonderer Berücksichtigung meiner neuen Nährböden.}

Seitdem der Erreger von Ulcus molle von Ducrey zuerst entdeckt wurde und ihm Reinkulturen gelungen waren, sind verschiedene Nährböden für die Streptobazillen angegeben worden. Darüber will ich hier nur ganz kurz referieren, um dann auf meinen neuen Nährboden für Streptobazillen überzugehen.

Reinkulturen auf Nährböden von Hautextrakten waren zuerst Istomanoff und Akspianz (1897), sowie später Langlet (1901) gelungen.

Anf Aszitesagar hat zuerst Maréchal (1898) und im Jahre 1899 auf Agar-Nutrose-Schweineserum O. v. Petersen Reinkulturen von Streptobazillen erzielt.

Sowinski (1908) war außer auf Aszitesagar auch in einer mit hämorrhagischem Exsudat versetzten Bouillon die Reinkultur gelungen.

Blutagar (aus einer Mischung von Kaninchen- oder Menschenblut und Fleischwasseragax (1:2) wurde zuerst von Besancon, Griffon und Le Sourd (1901) als der beste unter' den damaligen bekannten Nährböden für Streptobazillen empfohlen. Das flüssige Blut von Meerschweinchen, Kaninchen und Menschen benützte zuerst Himmel (1901), welches sich als Nährmedium sebr geeignet erwies. 
DaB Blutagar, Kondenswasser von Blutagarröhrchen und flüssiges Blut von Menschen, Kaninchen und Meerschweinchen als Nährböden für den Streptobazillus besser geeignet seien, als die obengenannten Nährböden, warde in letzter Zeit von vielen Autoren bestätigt (Majoc chi 1901, E. Tomas czewski 1903, Fischer 1903, Respighi 1903, Lips ch ütz 1905).

Auch nach meiner Erfahrung sind Blutagar, Kondenswasser desselben und flüssiges Blut die besten Nährmedien; es ist bei ihrer Herstellung und Benützung folgendes zu beachten:

Ich habe das Blut von Kaninchen aus der Art. carotis, bei Menschen aus der Ven. mediana, bei $\mathrm{HammeIn}$ aus der Ven. jugularis mittels sterilisierten langen Troikars entnommen and in sterilen, mit Glasperlen versehenen Glaskolben aufgefangen; dann wurde kräftig geschüttelt, um eine Gerinnung zu verhüten.

Als Zusatz zu Agar erscheint mir Kaninchenblut am besten, doch sind Menschen- und Hammelblut auch geeignet. Man wird öfters finden, daß die Streptobazillen, die schon mehrere Generationen hindurch auf Blutagar gut gewachsen waren, auf den unter den vorsichtigsten Kautelen dargestellten Nährböden ohne irgend welchen Grund nicht mehr üppig wachsen. Als Ursache kann man verschiedene Momente annehmen. Vor allem ist es aber wichtig, daß die Nährböden ziemlich feucht und weich sind. Dementsprechend muß man das Mengenverhältnis des flüssigen Blutes zum Fleischwasseragar, das gewöbnlich I : 2 beträgt, abändern.

Über 10 Tage im Eisschrank aufbewahrter Blutagar ist als Nährboden für Streptobazillen nicht mehr geeignet. Am besten ist frisch dargestellter Blutagar, worauf die Streptobazillen üppig wachsen. Am besten gedeihen sie in der $\mathrm{Nähe}$ des Kondenswassers der Blutagarröhrchen.

Flüssiges Blut ist ebenfalls ein gutes Nährmedium, doch wachsen die Streptobazillen in verdünntem Blut (Verdünnung des Blutes mit Bouillon $1: 2$ ) besser als im reinen Blut.

Im Kaninchenserum wachsen die Streptobazillen um so besser, je größer die Menge des gelösten $\mathrm{Hämoglobins} \mathrm{ist.} \mathrm{Im} \mathrm{Serum} \mathrm{von}$ Menschen und Hammeln gedeihen sie meistens nicht.

Ans flüssigen Nährböden sind die Bazillen sehr schwer auf festen Blutagar $z \mathfrak{u}$ übertragen, ebenso schwer sind sie von Blutagar auf Aszitesagar, Serumagar und halb koaguliertem Pferdeserum, worin sie schlecht wachsen, überzuimpfen.

Die Streptobazillen, die von mir gezüchtet warden, wuchsen nicht. auf gewöhnlichem Agar-Agar und in Bouillon.

Die erste Generation der Streptobazillen direkt aus dem Krankheitsherde wuchs auf Blutagar langsam und wurde erst. 
nach zwei Tagen deutlich sichtbar. In 3 bis 4 Tagen erreicht die Kultur das Maximum ihrer Entwicklung. Die Kolonien sind rund, ungefähr hanfkorngroß, über die Oberfläche des Blutagars halbkuglich herrorragend, meist im Zentrum leicht eingesunken, eine zentrale Delle zeigend, grauweiß oder leicht bräunlich-grauweiß, nicht konfluierend und haben eine ziemlich feste Konsistenz.

In der dritten Generation wachsen die Steptobazillen schneller, sie sind meist 24 Stunden nach der Impfung auf frischem Blutagar üppig entwickelt und erreichen nach 48 Stunden das Maximum ihrer Entwicklung. Sie haben ein etwas anderes Aussehen als die erste Generation, und zwar handelt es sich um tautropfenähnliche, stark glänzende, etwas kleinere, meist isolierte, oft in der Mitte eine zentrale Delle zeigende Kolonien.

Diese Streptobazillen sind noch lebensfähig nacb 50 Generationen, wenn man sie täglich auf neuen frischen Nährboden überimpft.

Das Aussehen einer Kultur, die einmal den Menschen passiert hat, ist das gleiche wie das oben geschilderte.

Die sovon mir gezüchteten Streptobazillen sind für den Menschen pathogen. Sie bilden 24 Stunden nach der Inokulation, wobei mittels Platinöse eine ganz geringe Menge einer 24stündigen Blutagarkultur nach Skarifikation mit einem scharfen Messer in die Haut unter streng aseptischen Maßregeln eingerieben wurde, zirka hanfkorngroße Pusteln mit einem grenzenden entzündeten Hof an der geimpften Hautstelle.

Diese Pusteln konfluieren zirka 3 Tage nach der Inokulation zu einer großèn Pustel, die mit schmutzig bräunlicher Kruste bedeckt ist. Am Boden der Kruste zeigt sich ein typisches Geschwür wie beim Ulcus molle. Im Pustelinhalt finden sich zahlreiche Streptobazillen. Aus dem Eiter der Pusteln gelang es, Streptobazillen-Reinkulturen zu erhalten. Das Geschwür heilt meist spontan in zirka 10 Tagen ab.

Die Übertragung einer 24stïndigen Blutagarkultur auf die Kornea und Genitalhaut von Kaninchen sowie auf die 
Genitalhaut von Meerschweinchen mißlang nach der beim Menschen ausgeführten Impfmethode.

Nach einer intrakutanen Injektion einer Streptobazillenemulsion, welche einer 24 Stunden alten Blutagarkultur entnommen und im Kondenswasser des Röhrchens. fein emulgiert worden war, entstand an der Genitalhaut der Kaninchen am nächsten Tage eine leichte entzündliche Anschwellung, die in der Mitte eine zirka hanfkorngroße Abszeßbildung aufwies, welche sich aber später nicht zu einem Geschwür umwandelte, sondern allmählich resorbiert wurde.

Da die Streptobazillen auf den gewöhnlichen Nährböden nicht wachsen und als festes Nährmedium Blutagar am besten ist, der aber stets frisch zubereitet werden muß, da es ferner nicht immer gelingt, das Blut vollkommen steril zu entnehmen, so ist eine Reinzüchtung von Streptobazillen nicht ganz einfach; außerdem sind die Blutnährböden tener.

Ich habe mich nun damit beschäftigt, brauchbare $\mathrm{N} \ddot{\mathrm{h}} \mathbf{r}-$ böden für Streptobazillen möglichst einfach und billig herzustellen.

Als Blut für die Näbrböden wurde defibriniertes $\mathrm{Hammelblut}$ vom Schlachthof gewählt, da Hammelblut sehr billig und leicht zu erhalten ist.

1. Dieses defibrinierte Hammelblut wurde in großen Glaskolben 2 bis $2^{1 / 2}$ Stunden lang bei $60^{\circ} \mathrm{C}$ im Wasserbad erhitzt, bis es halb geronnen war und eine schokoladenähnliche Farbe zeigte. Dieses so sterilisierte halb geronnene Blut muß vor dem Gebrauch tüchtig geschüttelt und möglichst fein emulgiert werden. Dann wird $3 \%$ iger Fleischwasseragar bei $100^{\circ} \mathrm{C}$ verflüssigt und auf $60^{\circ} \mathrm{C}$ abgekühlt, Diesen Aüssigen Fleischwasseragar mischt man mit dem sterilisierten Hammelblut im Verhältnis von 1:1 oder 2:1 und läßt diese Mischung in einem Röhrchen schräg erstarren.

Um die. Sterilisation dieser so gewonnenen Nährböden zu prüfen, läßt man die Röhrchen 24 bis 48 Stunden bei $38^{\circ}$ im Brutschrank stehen. Die Näbrböden haben die Farbe von Schokolade und ihre Oberfäche ist feucht, lackartig glänzend; das Kondenswasser ist fast k]ar oder nur etwas bräunlichrot verfärbt.

2. Defibriniertes Hammelblut wird mit dem gleichen Volumen von gewöhnlicher Bouillon gemischt, diese Mischung wie oben erhitzt und schräg gestellt. 
Ito.

3. Defibriniertes Hammelblut allein oder eine Mischung mit gewöhnlicher Bouillon in gleichen Mengen wird 20 Stunden bei $60^{\circ} \mathrm{C}$ im Wasserbade erhitzt, dann im Eisschrank aufbewahrt und am nächsten Tage nochmals erhitzt. Aus diesem sterilisierten Hammelblut oder der Mischung von Hammelblut und Bouillon stellt man wie oben schräge Blutagarröhrchen her.

4. Defibriniertes Hammelblut oder eine Mischung von defibriniertem Hammelblut mit gewöhnlicher Bouillon zu gleichen Teilen wird 1 bis $1^{1} / 2$ Stunden lang bei $70^{\circ} \mathrm{C}$ im Wasserbad erhitzt. Dann verfährt man wie oben geschildert.

Auf diesen 4 Nährböden wachsen die Streptobazillen in 24 Stunden ebenso üppig wie auf anderen Blutagarnährböden und erreichen nach 48 Stunden das Maximum ihrer Fntwicklung.

Das Aussehen dieser Kolonien sowie das mikroskopische Bild der so gezüchteten Streptobazillen sind die gleichen wie die auf dem anderen Blutagar gewachsenen Streptobazillen.

\section{Über das Streptobazillengift.}

Über Versuche mit den Giften der Streptobazillen ist bis jetzt nur wenig bekannt. Nach Angabe von Sowinsky (1908) zeigen die durch Alkoholfällung dargestellten Toxine von Streptobazillen eine lokale und allgemeine Wirkung, die lediglich an den Streptobazillenleib gebunden ist. Die von ihm gezüchteten Streptobazillen hatten Eigenbewegung und waren für Menschen und Tiere nicht pathogen. Es scheint mir aber auch hier sehr zweifelhaft, ob seine Bazillen auch wirklich Erreger des Ulcus molle waren.

Zur Beantwortung der Frage, ob das Streptobazillengift ein Endotoxin oder Exotoxin ist, habe ich folgenden Versuch angestellt:

Lös nng I. Aus einer großen Anzahl Kaninchenblutagarröhrchen, worauf die Streptobazillenkulturen 24 Stunden nach der Beimpfung sehr üppig aufgegangen und im Kondenswasser sogar sehr reichlich gewachsen waren, wurde, nachdem die Kolonien von der Oberfläche des Blutagars sehr gut entfernt worden waren, das Kondenswasser von vier Röhrchen gesammelt und mit $1 \mathrm{ccm}$ physiologischer Kochsalzlösung verdünnt. Diese Kondenswasserlösung, in der massenhaft Streptobazillen nachweisbar waren, wurde durch sterilisierte dicke Gaze flltriert, 3 Stunden bei $45^{\circ} \mathrm{C}$ im Wasserbad erhitzt, um die Bazillen abzutöten, und im 
Schüttelapparat über 24 Stunden geschüttelt, um eine Embolie bei den venösen Injektionen $\mathrm{zu}$ vermeiden.

Ferner stellte ich mir eine $\mathrm{L} \ddot{\text { ö }} \mathrm{ung}$ II dar, indem ich die oben angegebene Kondenswasserlösung (Lösung I) durch ein sterilisiertes Tonfilter filtrierte und den Filterrückstand, in dem wieder sehr viel Streptobazillen nachzuweisen waren, mit gewöhnlichem storilen Kondenswasser von Kaninchenblutagarröhrchen (Kondenswasser von 4 Röhrchen, auf deren Blutagar keine Bazillen gezüchtet waren, mit $1 \mathrm{ccm}$ phys. Kochsalzlösung verdünnt) bis zum gleichen Volumen verdünnte und dann wieder wie oben angegeben sterilisierte.

Eine Lösung III wurde hergestellt, indem das Filtrat der zweiten Lösung, worin keine Streptobazillen nachweisbar waren, drei Stunden bei $45^{\circ} \mathrm{C}$ im Wasserbad sterilisiert wurde. (Lösung III.)

\section{Versuch mit Lösung 1.}

Intravenöse Injektion bei gesunden Meerschweinchen: ${ }^{1}$ )

\begin{tabular}{|c|c|c|c|}
\hline $\begin{array}{c}\text { Nr. des } \\
\text { Tieres }\end{array}$ & Gowicht & $\begin{array}{l}\text { Dosis der } \\
\text { Lösnng I pro } \\
100 \mathrm{~g} \text { Tier } \\
\text { intravenös }\end{array}$ & 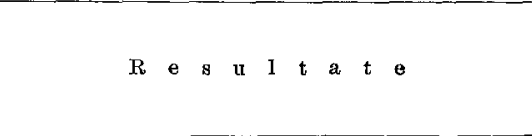 \\
\hline 15 & 180 & $1 \cdot 0$ & Fast gesund. \\
\hline 14 & 190 & $1 \cdot 5$ & Unruhig, sträubt die Haare. \\
\hline 13 & 180 & $2 \cdot 0$ & $\begin{array}{l}\text { Unruhig, nach } 7 \text { M. leichte Krämpfe, } \\
\text { erholt sich wieder. }\end{array}$ \\
\hline 19 & 180 & $2 \cdot 5$ & $\begin{array}{l}\text { Sofort Seitenlage, nach } 2 \text { Mon. tot, } \\
\text { Lunge leicht aufgebläht, hämorrhag. } \\
\text { Blut halb geronnen. }\end{array}$ \\
\hline
\end{tabular}

Das Kondenswasser, worin die Streptobazillen sehr üppig wuchsen, ist nicht so giftig für normale Meerschweinchen. Erst bei $2.5 \mathrm{ccm}$ pro $100 \mathrm{~g}$. Tier beginnt die tödliche Dosis; unter einer Dosis von $2{ }^{\circ} 0$ bleiben die Tiere am Leben. injiziert:

Versuch mit Lösung II. gesunden Meerschweinchen intravenös.

1) Ich habe absichtlich diese Lösungen intravenös injiziert, da sie bei intraperitonealen Injektionen für gesunde Meerschweinchen nur in großer Dosis tödlich wirken.

Arch, f. Dermat, u. Syph. Bd. CXVI. 
Ito.

\begin{tabular}{|c|c|c|c|}
\hline $\begin{array}{l}\text { Nr. des } \\
\text { Tieres }\end{array}$ & $\begin{array}{c}\text { Ge- } \\
\text { wicht }\end{array}$ & $\begin{array}{l}\text { Dosis der } \\
\text { Löbung II pro } \\
100 \text { g Tier } \\
\text { intravenös }\end{array}$ & $R \quad e \quad s \quad l \quad l \quad a t e$ \\
\hline 45 & 200 & $2 \cdot 0$ & $\begin{array}{l}\text { Unruhig, leichte Dyspnoe. Erholt } \\
\text { sich wieder. }\end{array}$ \\
\hline 20 & 180 & $2 \cdot 5$ & $\begin{array}{c}\text { Sofort nnruhig. dyspnoisch, } 5 \text { St. nach } \\
\text { Injektion tot, Lungen leicht } \\
\text { aufgebläht, hämorrhag. Blut halb } \\
\text { geronnen. }\end{array}$ \\
\hline
\end{tabular}

Die Giftigkeit von Lösung II ist die gleiche wie von Lösung $\mathbf{I}$. injiziert:

Versuch mit Lösung III gesunden Meerschweinchen intravenös

\begin{tabular}{|c|c|c|c|}
\hline $\begin{array}{l}\text { Nr. des } \\
\text { Tieress }\end{array}$ & $\begin{array}{c}\text { Ge- } \\
\text { wicht }\end{array}$ & $\begin{array}{l}\text { Dosis der } \\
\text { Lösung IIr } \\
\text { pro } 100 \mathrm{~g} \text { Tier } \\
\text { intravenös }\end{array}$ & $\begin{array}{lllllllll}R & \theta & \mathbf{s} & \mathbf{u} & \mathbf{l} & \mathrm{t} & \mathrm{a} & \mathrm{t} & \boldsymbol{\theta}\end{array}$ \\
\hline 21 & 180 & $2 \cdot 5$ & Unruhig, strätubt die Haare. \\
\hline 25 & 220 & $3 \cdot 5$ & $\begin{array}{c}\text { Sofort Seitenlage, tonische Krämpfe, } \\
\text { nach } 3 \mathrm{M} \text {. erholt es sich wieder, } \\
\text { nach } 30 \mathrm{M} \text {. starke Dyspnoe. }\end{array}$ \\
\hline 24 & 200 & $4 \cdot 0$ & $\begin{array}{l}\text { Sofort Seitenlage, erholt sich aber } \\
\text { wieder, nach } 30 \text { M. starke Dyspnoe. }\end{array}$ \\
\hline
\end{tabular}

Die Giftigkeit der Lösung III ist wesentlich geringer. Erst 4.0 pro $100 \mathrm{~g}$ Tier ist eine fast tödliche Dosis. Daraus kann man schließen, daß die Streptobazillen ihr Gift nicht sezernieren, sondern daß sie an die Bakterienleiter gebunden sind.

Mitunter kommt es vor, daß die Giftigkeit der Bakterienemulsion nach der Filtration mit dem Tonerdefilter abnimmt, wodurch Fehler entstehen. Um diesen Fehler zu vermeiden, habe ich eine Lösung IV in folgender. Weise dargestellt:

Das Kondenswasser von 4 Röhrchen des mit Streptobazillen bewachsenen Blutagar von Kaninchenblut mit 1.0 phys. Kochsalzlösung verdünnt, mit Tonerdefilter filtriert und wie das erstere erhitzt.

Die Giftigkeit der Lösung IV ist fast ebenso groß wie die der Lösung III. 
Ich möchte besonders hervorheben, daß gesunde Meerschweinchen eine derartig große Menge von $4 \mathrm{ccm}$ (pro $100 \mathrm{~g}$ Tier) Filtrat des Kondenswassers, in welchem die Streptobazillen sehr üppig oder nicht gewachsen waren, als intravenöse Injektion gut vertragen können.

Lösung I und II sowie III und IV sind bezüglich ibrer Giftigkeit fast gleich. Lösungen I und II sind deutlich giftiger als Lösungen III und IV. Daß die Lösung III nicht so giftig ist als die Lösungen I und II, kann nicht etwa durch die Absorption des Giftes im Tonerdefilter beim Filtrieren erklärt werden, sondern muß als ein Fehlen des Streptobazillengiftes im Filtrat angesehen werden; $d . h$. also, das Toxin ist an die Bazillen gebunden und wird nicht von ihnen abgegeben. Erst nach Zerstörung der Bazillenleiber wird das Gift frei.

Nach diesen Ergebnissen ist es nun leichter erklärbar, daß bei Bubokranken bei der Kutireaktion auch nach der Injektion von abgetöteten Streptobazillenemulsionen eine $A b$ szeßbildung zustande kommt.

Um den Grad der Giftigkeit der Streptobazillen bzw. des Vakzins festzustellen, habe ich folgende Streptobazillenemulsion hergestellt:

Versuch 1: Die Kolonien von 4 Kaninchenblutagar-Röhrchen wurden in $1 \mathrm{ccm}$ phys. Kochsalzlösung möglichst fein emulgiert und 2 Stunden lang bei $60^{\circ} \mathrm{C}$ im Wasserbad abgetötet. Die so gewonnene Emulsion wurde in einem sterilisierten, mit kleinen Glasperlen versehenen Glaskolben über 24 Stunden im Schüttelapparat geschüttelt, wieder um eine Embolie bei der intravenösen Injektion zu vermeiden.

Diese Emulsion wurde normalen Meerschweinchen in die Vene injiziert, um den Grad der Giftigkeit festzustellen.

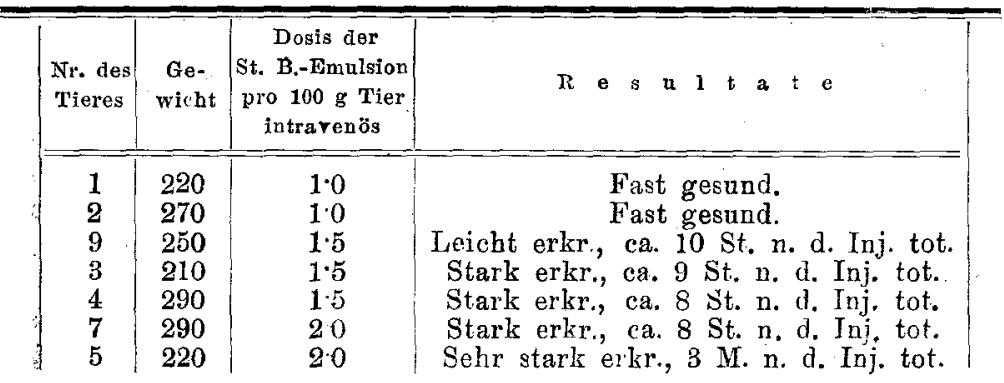


Die Streptobazillenemulsion wirkt nicht unter 1.0 pro $100 \mathrm{~g}$ Tier tödlich, ist aber über $1.5 \mathrm{ccm}$ tödlich; bei einer Dosis von $2 \mathrm{ccm}$ sterben alle Tiere in kurzer Zeit.

\section{Öber Immunität und Anaphylaxie durch Streptobazillen.}

Nach den klinischen und experimentellen Erfahrungen mubte man im allgemeinen annehmen, daß eine Immunität bei Menschen and Tieren durch D u crey sche Streptobazillen nicht zustande kommt. Sehr interessant waren daher die Angaben von Thibierge, Ravaut und Le Sourd, die am Lidrand bei Affen nach wiederholten Impfungen mit Streptobazillen eine regionäre Immunität erzielen konnten. Diese Angabe von Thibierge veranlaßte mich nun zu der Frage, ob bei Vorbehandlung mit Streptobazillen eine aktive oder eine passive Immunisierung zustande kommt oder nicht.

Zur Beantwortung dieser Frage habe ich folgenden Versuch gemacht:

Bei einem Kollegen wurden:

9./X. einige Tropfen von Streptobazillenvakzin am linken Oberarm intrakutan injiziert.

10./X. Ganz leichte Rötung an der Impfstelle, keine subjektiven Klagen. Streptobazillenvakzin $0.4 \mathrm{~cm}$ in die rechte Glutäalgegend intrakutan, jedoch etwas tiefer als sonst bei Kutireaktion injiziert wurde.

11./X. Am linken Oberarm keine Rötung, Jeichter Schmerz in der rechten Glutäalgegend, leichtes Fieber $\left(375^{\circ} \mathrm{C}\right)$.

14/X. Streptobazillenvakzin $0.8 \mathrm{com}$ in die linke Glutäalgegend intrakutan injiziert.

15./X. Der Schmerz in der linken Glutäalgegend ist stärker als bei der ersten Injektion.

18./X. Streptobazillenvakzin $1.6 \mathrm{~cm}$ in die reohte Glutäalgegend intrakutan injiziert.

19./X. Die Haut an der Injektionsstelle ist sehr stark gerötet, der Schmerz stärker als bei der letzten Injektion.

27./X. Am linken Oberarm, wo am 9./X. das Vakzin injiziert worden war, wird nach Jeichter Skarifikation der Haut mit dem scharfen Messer eine kleine Menge lebender Streptobazillen (24 Stunden alt auf Kaninchenblutagar gezïchtet) unter streng aseptischen Maßregeln eingerieben. Am rechten Oberarm werden einige Tropfen Streptobazillenvakzin intrakutan injiziert.

28./X. Am linken Oberarm mehrere zirka hanfkorngroße Pusteln mit einem roten Hof, leicht schmerzhaft. In diesem Pusteleiter werden mikroskopisch zahlreiche typische Streptobazillen nachgewiesen. Die 
bakteriologische Untersuchung des Eiters ergibt eine Reinkultur von Streptobazillen.

Am rechten Oberarm sehr starke, über zweimarkstückgroße entzündliche Rötung mit starker Induration und zentraler kleiner Pustelbildung wie bei der Kntanreaktion Bubokranker; stark schmerzhaft.

24./X. Pustel am l. Oberarm konfluiert zu einer fingerspitzgroßen Pustel, deren Grund ein typisches Geschwür zeigt.

30./X. Geschwür am linken Oberarm mit dicker schmutzigbräunlicher Kruste bedeckt und seichter geworden. Reaktive Entzündung am rechten Oberarm deutlich abgenommen, aber noch daumenspitzgroß und stark gerötet, induriert und sehr schmerzhaft.

31./X. Geschwür am linken Oberarm fast geheilt; abermals in die Nähe dieses Geschwüres eine 24 Stunden alte Streptobazillenkultur wie am 27./X. inokuliert.

1./XI. Fingernagelgroße Pustel mit stark entzündlichem roten Hof. Im Eiter dieser Pustel viele Streptobazillen mikroskopisch nachgewiesen und als Reinkultur kulturell, Der Grund der Pustel zeigt wieder ein typisches Geschwür.

2./XI. Geschwür mit dicker, schmutzigbräunlicher Kruste bedeckt, darunter mäßige Menge von dickem Eiter, in dem Streptobazillen in Masse nachgewiesen wurden.

4./XI. Geschwür noch mit dicker Kruste bedeckt, entzündlicher roter Hof deutlich abgeblaßt.

6./XI. Geschwür fast geheilt.

Kontrollversuch.

31./X. Am linken Oberarm Reinkultur von Streptobazillen (24 Stunden alt) wie im Versuch inokuliert.

1./XI. Fingernagelgroße Pustelbildung mit stark entzündlichem roten Hof. Im Eiter sehr viel Streptobazillen mikroskopisch nachweisbar. Reinkultur von Streptobazillen. Der Grund der Pustel zeigt ein typisches Geschwür.

2./XI. Geschwür mit dicker schmutzigbräunlicher Kruste bedeckt, darunter dicker Eiter in massiger Menge, in welchem noch viele Streptobazillen nachgewiesen werden konnten.

4./XI. Die Kruste vertrocknet; Entzündung deutlich zurückgegangen.

6./XI. Geschwür fast geheilt.

Daraus ergibt sich folgendes:

Die Kutireaktion wurde, wie schon früher beschrieben, nach der Vakzinvorbehandlung deutlich stärker als bei der erstmaligen Vakzininjektion.

Die Inokulation mit Streptobazillen ist $\mathrm{nach}$ der Vakzinvorbehandlung ebenso positiv wie ohne 
Vakzinvorbehandlung. Die beiden Geschwüre nach der Inokulation heilten spontan in zirka 6 Tagen.

Außerdem habe ich noch einen Inokulationsversuch bei einem Kranken gemacht, bei dem ein Ulcus molle am Penis und ein dolenter Bubo in der linken Inguinalgegend nach einer Vakzininjektion fast geheilt waren. Auch bei diesem Fall gelang die Reinokulation mit Streptobazillen.

Es kommtalso im Veriaufeder Streptobazillenaffektion ebenso wie nach der Vakzinvorbehandlung keine aktive Immunität des Organismus zustande.

Versuche über eine passive Immunität.

Zwei normale Kaninchen wurden mit Streptobazillenvakzin intraperitoneal in steigenden Dosen $(1 \cdot 0,1 \cdot 5,3.0)$ dreimal in zirka fünftägigen Intervallen injiziert. Zwei Wochen nach der letzten Injektion wurde den Kaninchen Blut entnommen und der Pfeiffersche Versuch an zwei gesunden Meerschweinchen ausgeführt:

Nach der intraperitonealen Injektion der lebenden Streptobazillenemulsion mit einem normalen und mit dem "Immun"serum von Kaninchen, trat erst nach $2 \frac{1}{2}$ Stunden eine deutliche Verminderung der Streptobazillen in der Peritonealhöhle ein, sonst konnten keine morphologischen Unterschiede $z$ wischen den beiden nachgewiesen werden.

Außerdem wurde noch ein Versuch angestellt, indem ich Meerschweinchen Antigen und Antiserum gleichzeitig intravenös injizierte.

\section{Versuch 2.}

Als Antigen wurde die Streptobarillenemulsion, die bei Versuch 1 gebraucht wurde, verwendet.

Als Antiserum diente inaktives Inmmunserum der Kaninchen, die mit Streptobazillenemulsion in steigenden Dosen viermal intraperitoneal injiziert worden waren. 


\begin{tabular}{|c|c|c|c|c|}
\hline 要 & 营 & $\begin{array}{c}\text { Dosis der St.- } \\
\text { B.-Emulsion } \\
\text { pro } 100 \mathrm{~g} \text { Tier }\end{array}$ & $\begin{array}{l}\text { Dosis des Ka- } \\
\text { ninchenserums } \\
\text { pro } 100 \mathrm{~g} \text { Tier }\end{array}$ & 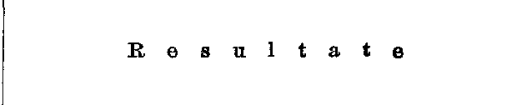 \\
\hline 9 & 180 & $1 \cdot 0$ & $\begin{array}{l}\text { norm. Kanin- } \\
\text { chenserum } \\
0.5\end{array}$ & $\begin{array}{l}\text { Fast gesund, } 24 \text { Stunden nach der } \\
\text { Injektion tot. }\end{array}$ \\
\hline 11 & 180 & $1 \cdot 0$ & $\begin{array}{l}\text { vorbeh. Kanin- } \\
\text { chens. Nr. } 175 \\
0.5\end{array}$ & $\begin{array}{l}\text { Sofort Krämpfe, } 2 \text { M. stark dyspnoisch, } \\
\text { Seitenlage, } 4 \text { St. n. d. Inj. tot. } \\
\text { Lungen aufgebläht, leicht hämorrhag. }\end{array}$ \\
\hline 12 & 180 & $1 \cdot 0$ & $\begin{array}{l}\text { vorbeh. Kanin- } \\
\text { chens. } \mathrm{Nr} .134 \\
0.5\end{array}$ & $\begin{array}{l}\text { Sehr starke Dyspnoe, } 5 \text { St. n. d. Inj. } \\
\text { tot. Lungen aufgebläht, leicht hämor- } \\
\text { rhagisches Blut nicht geronnen. }\end{array}$ \\
\hline 12 & 260 & $\begin{array}{c}\text { physiologische } \\
\text { Kochsalzlösung } \\
1.0\end{array}$ & $\begin{aligned} \text { dto. } & \\
0.5 & \end{aligned}$ & $\begin{array}{l}\text { Fast gesund, am nächsten Tage } \\
\text { leicht erkrankt. }\end{array}$ \\
\hline
\end{tabular}

Man sieht also, da $\beta$ die Mischung von Streptobazillenvakzin und Kaninchenimmunserum deutlich giftiger ist als die von Streptobazillenvakzin und normalem Kaninchenserum. Vorbehandeltes Kaninchenserum besitzt somit keine neutralisierende Eigenschaft gegen das Gift der Streptobazillen; es erweist sich jedoch giftige $r$ beim Vorhandensein von Streptobazillenvakzin. Aus diesem Ergebnisse erklärt es sich, daß eine Immunität gegen Streptobazillen nach der Vorbehandlung der Kaninchen mit Vakzin nicht zustande kommt, sondern es läßt sich vermuten, daß im Serum des betreffenden Kaninchens vielleicht der anaphylaktische Antikörper Friedbergers neu gebildet wird. Nach Mitas und meinen Versuchen gibt es solche Fälle, wo normales Kaninchenserum oder das mit einem Antigen vorbehandelte Kaninchenserum manchmal für Meerschweinchen stark giftig ist.

Ich habe, wie die nächste Tabelle zeigt, eine geringere Menge als in Tabelle I von Kaninchenserum mit einer ebenfalls geringeren Menge ( $1 / 3$ tödl. Dosis) Streptobazillenvakzin gesunden Meerschweinchen intravenös injiziert.

Eine Verbindung ron einem Drittel der tödlichen Dosis Streptobazillenemulsion und einer geringen Menge von Antiserum wirkt für gesunde 
Nueerschweinchen tödlich, während eine Verbindung ron S.treptobazillenemulsion und einer geringen Menge normales Kaninchenserum an Stelle des Antiserums nicht tödlich wirkt.

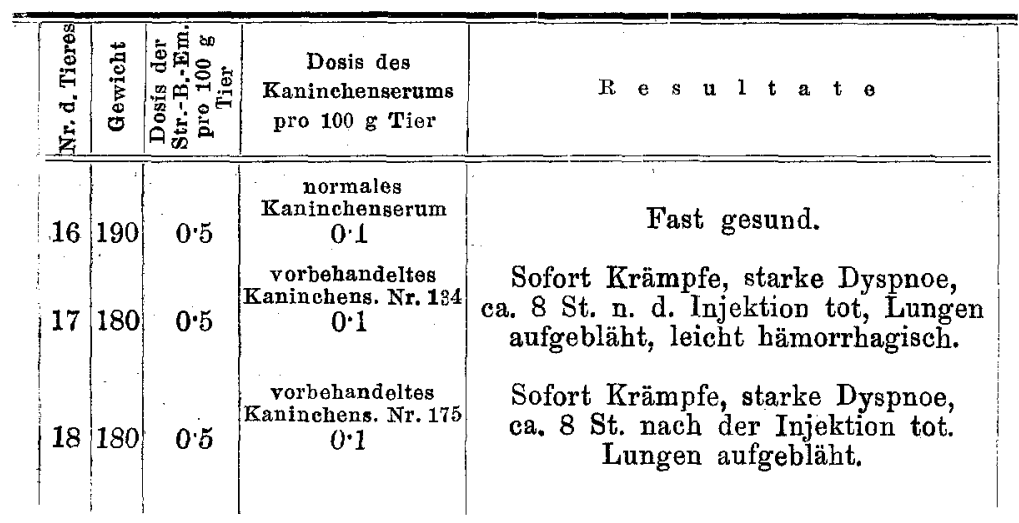

Durch die oben gezeigten Versuche scheint es mir erwiesen, daß eine Bildung bakterizider Substanzen nach einer Vorbehandlung mit Streptobazillenemulsion sich nicht nachweisen läßt. Nach Injektionen einer Mischung von "Antiserum" mit Streptobazillen scheint Anaphylotoxinvergiftung einzutreten.

\section{Über passive Anaphylaxie.}

Nach meinen Ergebnissen, daß der Vorbehandlung mit Streptobazillenvakzin ein anaphylaktischer Zustand im Organismus folgt, interessierte es mich, nach einer passiven Anaphylaxie zu forschen, die klinisch-diagnostisch ron Wichtigkeit sein könnte.

\section{Versuch 3.}

Gesunde Meerschweinchen wurden mit $0.3 \mathrm{ccm}$ Streptobazillenemulsion, welche bei Versuch 1 verwendet wurde, subkutan injiziert. 16 Tage nach der Injektion wurde den betreffenden Meerschweinchen Blut entnommen.

Mit diesem Meerschweinchenserum in verschiedenen Mengen wurden gesunden Meerschweinchen intraperitoneale Injektionen gemacht. Dann erfolgte die Injektion von Streptohazillenemulsion wie in Versuch 1. 


\begin{tabular}{|c|c|c|c|c|c|}
\hline 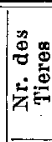 & $\mid \begin{array}{l}\vdots \\
\vdots \\
0 \\
\ddot{z} \\
0 \\
0 \\
0\end{array}$ & 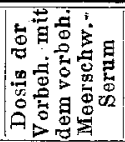 & 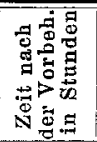 & 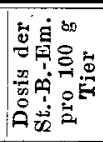 & $\begin{array}{lllllllll}R & e & s & \mathbf{l} & \mathrm{t} & \mathrm{a} & \mathrm{t} & \mathrm{e}\end{array}$ \\
\hline 36 & 180 & $3 \cdot 0$ & ca. 24 & 05 & $\begin{array}{l}\text { Leicht erkrankt, ca. } 24 \text { St. n. d. Inj. } \\
\text { tot. Lungen weiß, aufgebläht. }\end{array}$ \\
\hline 37 & 180 & $2 \cdot 0$ & " & 0.5 & $\begin{array}{l}\text { Unruhig, dyspnoisch, ca. } 24 \text { St. n. d. } \\
\text { Inj. tot. Lungen weiß, aufgebläht. }\end{array}$ \\
\hline 38 & 180 & $1 \cdot 0$ & $n$ & 0.5 & $\begin{array}{l}\text { Starke Dyspnoe, Krämpfe, ca. } 4 \mathrm{St} \text {. } \\
\text { n. d. Inj. tot. Lungen aufgebläht, } \\
\text { Blut im Herz nicht geronnen. }\end{array}$ \\
\hline 39 & 190 & 0.5 & $\pi$ & 0.5 & $\begin{array}{l}\text { Dyspnoe, ca. } 4 \text { St. n. d. Inj. tot. } \\
\text { Lungen leicht hämorrhag. aufgebläht. }\end{array}$ \\
\hline
\end{tabular}

Die Menge des injizierten Serums der mit Streptobazillenemulsion vorbehandelten Meerschweinchen betrug $0 \cdot 5-1 \cdot 0 \mathrm{ccm}$. Dies erscheint mir zur Vorbehandlung geeigneter als die größeren Mengen von $2-3 \mathrm{ccm}$.

Um die Injektionsmenge der Streptobazillenemulsion nach der Serumvorbehandlung noch genauer zu bestimmen, wurden verschiedene Mengen derselben intravenös injiziert.

Dosis der Vorbehandlung mit vorbehandeltem Meerschweinchenserum intraperitoneal $0 \cdot 8$. Zeit zwischen den einzelnen Injektionen zirka 24 Stunden.

Nach diesem Versuche ist $0.25-0.5 \mathrm{ccm}$ von Streptobazillenemulsion in Verbindung mit dem Antiserum pro $100 \mathrm{~g}$ Tier als tödliche Dosis anzusprechen, während dieselbe Emulsion allein in den Dosen von 1.5 bzw. 2.0 normale Meerschweinchen tötet.

Kontrolle:

Vorbehandlung mit gesundem Meerschweinchenserum in verschiedenen Mengen $(2 \cdot 0,1 \cdot 0,0.5 \mathrm{ccm}$ i. p.), Injektion mit der gleichen Streptobazillenemulsion $(0.5 \mathrm{ccm}$ pro $100 \mathrm{~g}$ Tier $)$ wie oben, zirka 24 Stunden später. Alle Meerschweinchen blieben nach der Injektion von Streptobazillenemulsion rollkommen gesund.

$\mathrm{Nach}$ der Injektion des Serums ron Meerschweinchen, welche mit Streptobazillenemulsion 
vorbehandelt waren, nimmt die Giftigkeit der Streptobazillenemulsion bei den betreffenden Meerschweinchen deutlich, und zwar ungefähr ein Drittel zu, während die Giftigkeit derselben Emulsion bei den mit normalem Meerschweinchenserum vorbehandelten Tieren wie im Versuche 1 die gleiche bleibt.

Auf Grund dieses Resultates stellte ich analoge Versuche mit menschlichem Serum von Bubokranken an, um diese interessante Tatsache bei zweifel. haften Fällen ron Streptobazillenaffektionen als diagnostisches Hilfsmittel zu verwerten. Zur Kontrolle diente normales menschliches Serum.

\section{Versuch 4 .}

Vorbehandlung mit Serum eines Patienten, welcher an Ulcus molle und dolenten Bubo leidet, intraperitoneal einem normalen Meerschweinchen injiziert. Injektion der gleichen Streptobazillenemulsion wie in Versuch 1.

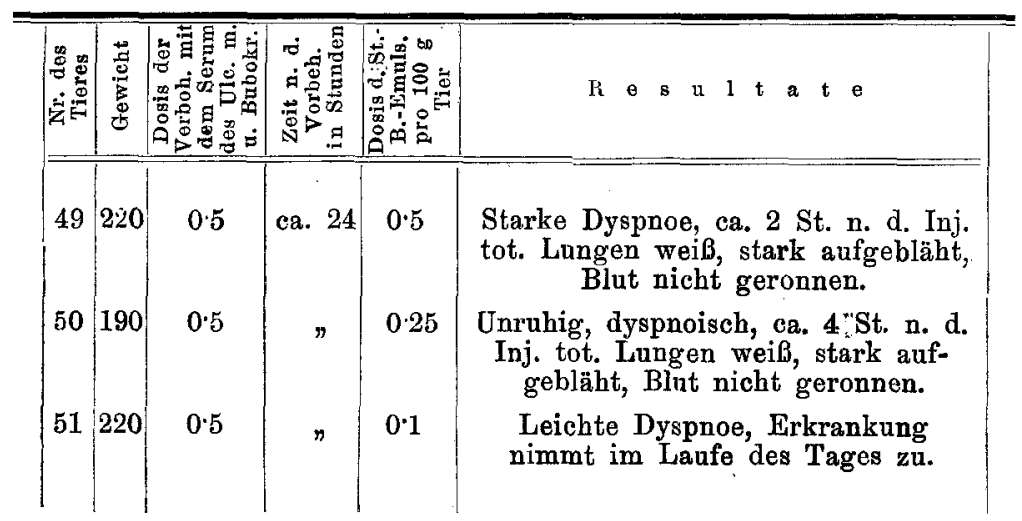

Als Resultat ergibt sich folgendes: Bei der Injektion von Serum Ulcus molle- und Bubo-Kranker nimmt die tödliche Dosis der Bazillenemulsion weniger ab als in Tabelle 2, und zwar ungefähr um ein Drittel.

Intraperitoneale Vorbehandlung von Meerschweinchen mit dem Serum eines Kranken, welcher an Ulcus molle und dolentem Bubo litt, zur Zeit des Versuches aber schon geheilt war. 
Injektion der gleichen Streptobazillenemulsion wie im Versuch 1.

In diesem Falle ist die tödliche Dosis der Streptobazillenemulsion gleich der in der nächsten Tabelle 2 (tödliche Dosis $0^{\circ}$ ).

Als Kontrolle: Vorbehandlung normaler Meerschweinchen mit gesundem Menschenserum. Intraperitoneale Injektion der gleichen Streptobazillenemulsion wie in Versuch 1 intravenös.

\begin{tabular}{|c|c|c|c|c|c|}
\hline 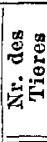 & 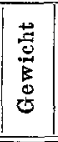 & 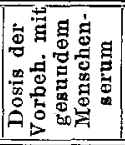 & 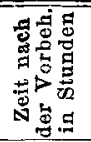 & 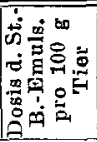 & $\mathrm{E}$ es $\mathrm{s}$ th $\mathrm{t}$ a $\mathrm{t}$ e \\
\hline 34 & 180 & 0.5 & ca. 25 & 0.5 & $\begin{array}{l}\text { Fast gesund, ca. } 10 \mathrm{St} \text {. n. d. Inj. tot. } \\
\text { Lungen leicht aufgebläht. }\end{array}$ \\
\hline 35 & 180 & 0.5 & $n$ & 025 & Vollkommen gesund. \\
\hline
\end{tabular}

Pro $100 \mathrm{~g}$ Tier sind $0.5 \mathrm{ccm}$ dieser Emulsion tödlich.

Die tödliche Dosis der Streptobazillenemulsion für vorbehandelte Meerschweinchen beträgt $0.5 \mathrm{ccm}$ pro $100 \mathrm{~g}$ Tier in den Fällen, wo Serum von gesunden Menschen oder geheilten Bubokranken zur Vorbehandlung gebraucht wurde, dagegen nimmt die tödliche Dosis zirka um die Hälfte ab, wenn Serum von Ulcus molle- und Bubokranken zur Vorbehandlung verwendet worden war.

Nach diesen Versuchen scheint es also, daß eine passive Übertragung der Anaphylaxie mit dem Serum Ulcus nolle- und Bubokranker zustande kommt. Denn Vorbehandlung von Meerschweinchen mit derartigem Serum macht die Tiere gegen nachfolgende Streptobazilleneinspritzungen in zweifach geringerer Dosis empfindlich, als dies nach Vorbehandlung mit normalem Menschenserum oder Serum von geheilten Bubopatienten der Fall ist.

\section{Präzipitationsversuche.}

Über Präzipitationsversuche mit Streptobazillen des Ulcus molle ist bisher nichts bekannt.

\section{Versuch 5 .}

Darstellung des Immunserums: Zwei Kaninchen wurden mit Streptobazillenvakzin dreimal vorbehandelt, zirka 
zwei Wochen nach der letzten Injektiou wurde das Blut entnommen und das Serum zum Versuch verwendet.

Als Antigen diente das Streptobazillenvakzin, welches bei der Kutireaktion gebraucht wurde, aber ohne Karbolsäurezusatz. Das Vakzin wurde in einem sterilen Reagenzglase zwei Tage lang im Eisschrank aufbewahrt, um die Bazillenleiber am Bodensatz absetzen zu lassen. Der oberste klare Teil des Vakzins wurde als Kulturfiltrat benutzt.

Bei der Ausführung wurde das von Uhlenhuth angegebene Gestell gebraucht.

Resultat: Bei dem Serum von vorbehandelten Kaninchen war die Präzipitation in der Verdünnung (1:40) positiv, während sie bei Kontrolle mit dem Serum von gesunden Kaninchen negativ ausfiel.

Wenn auch die Präzipitation nicht so hochgradig ist, wie bei dem Serum des mit Hammelserum vorbehandelten Kaninchen, so sieht man doch im Vergleich mit dem normalen Kaninchenserum einen deutlichen Unterschied.

Nach diesem Ergebnisse habe ich meine Präzipitationsversuche mit aktivem Serum verschiedener Patienten, namentlich Ulcus molle- und Bubokranker angestellt.

Das Antigen war das gleiche wie im Versuch 5, aber mit physiol. Kochsalzlösung I : 10 verdünnt.

Als Kontrolle wurde an Stelle des Antigen phys. Kochsalzlösung verwendet.

Resultat: Bei Gesunden fiel der Präzipitationsversuch stets negativ aus. Von 7 Kranken, die an Ulcus molle oder Bubonen litten, reagierten 5 positiv, 2 negativ. Dabei zeigten drei dieser 5 positiven Fälle in der Kontrolle mit physiol. Kochsalzlösung statt Antigen ebenfalls Präzipitation, so daß eine Verwertbarkeit der Präzipitationsresultate sehr zweifel haft ist.

\section{Agglutinationsversuche.}

Bis jetzt existieren keine Angaben über Agglutinationsversuche mit Streptobazillen. Meine Versuche habe ich folgendermaßen ausgeführt: 
Als Bazillenaufschwemmung dienten Reinkulturen von Streptobazillen aus 10 Blutagarröhrchen, die 24 Stunden alt waren. Die Bazillen wurden in $1.5 \mathrm{ccm}$ phys. Kochsalzlösung möglichst fein verteilt und diese Emulsion in einem sterilen, mit kleinen Glasperlen versehenen Glaskolben im Schüttelapparat zirka 24 Stunden lang geschüttelt. Zum Versuch wurden je 3 Tropfen dieser Bazillenaufschwemmung pro Reagenzgläschen verwendet.

Als Immunserum wurde das Serum eines Kaninchens genommen, welches mit Streptobazillenvakzin dreimal vorbehandelt war. Sicbere Resultate waren jedoch, da normales. Kaninchenserum noch bis 1:100 agglutinierte, $\mathrm{nicht} \mathrm{zu}$ erzielen.

Somit scheint auch die Agglutinationsmethode, ebenso wie die Präzipitationsmethode keinen klinisch-diagnostischen Wert für die Streptobazillenaffektionen zu haben.

\section{Komplementablenkungsversuch.}

Es wurden schließlich noch die Seren von Bubokranken, sowie die Seren mit Streptobazillen vorbehandelter Kaninchen nach der Methode der Komplementablenkung geprüft, ohn e dak jedoch verwertbare Resultate erzielt werden konnten.

\section{Resümee :}

1. Die Intrakutanreaktion mit einem aus Ducreyschen: Streptobazillen hergestellten Vakzin ist spezifisch und kann als ein Hilfsmittel zur Sicherung der klinischen Diagnose in Betracht kommen.

2. Eine Streptobazillenvakzinbehandlung bei Bubonen liefert schnelle und gute Resultate.

3. Die heftigen Erscheinungen des Bubo bei Ulcus molle entstehen vielleicht nicht nur durch direkte Wirkung der Streptobazillen allein, sondern durch gleichzeitige anaphylaktische Reaktionen des Organismus.

4. Zur Darstellung von Streptobazillen -Nährböden ist. defibriniertes Blut am geeignetsten.

Als flüssige Näbrböden sind Blutbouillonmischungen (1:2), besser als das unverdünnte Blut.

5. Die von mir angegebenen Nährböden, auf denen die Streptobazillen üppig wachsen, sind einfacher und billiger als die bisherigen. kokken.

Diese Nährböden sind auch gute Nährmedien für Gono-

6. Streptobazillen sind noch lebensfähig nach 50 Gene- 
rationen; wenn man sie täglich auf neue frische Nährböden überimpft.

7. Das Giit der Streptobazillen ist an den Bazillenleib gebunden (Endotoxin).

8. Die von mir dargestellte Streptobazillenemulsion wirkt bei gesunden Meerschweinchen unter einer Dosis von $1 \mathrm{ccm}$ pro $100 \mathrm{~g}$ Tier nicht tödlich, bei einer Dosis über $2 \mathrm{ccm}$ tritt meist in kurzer Zeit der Tod cin.

9. Durch Vakzinvorbehandlung kommt keine aktive Immunität im Organismus zustande.

10. Ebenso ist keine passive Immunität nachweisbar.

11. Durch Vorbehandlung mit Vakzin oder bei Verlauf der Streptobazillenaffektion kann Überempfindlicbkeit entstehen.

Die passive Übertragung der Anaphylaxie ist sowohl mit Serum anaphylaktischer Meerschweinchen als mit dem Serum von Bubokranken möglich.

12. Die Präzipitation, Agglutination und Komplementablenkung ergibt weder mit dem Serum vorbehandelter Tiere noch mit Patientenserum verwertbare Resultate.

\section{Literatur.}

1. Besancon, Griffon et Le Sourd: Pressemed. 1900, Nr. 10. p. 385. Soc. de biologie, Seance 8./XII. Annal. de dermat. et syph. 1901. 2. Babes, Kolle-Wassermanns Handbuch der pathol. Mikroorganismen. 1903، Bd. III.

3. Colom bini. Gaz, degli aspedali, 1896. Bd. XXV.

4. Fischer F. Dermat, Zeitschrift. 1903. Bd. X.

5. Himmel. Annal. Pasteur. 1901. Vol. XV. p. 928.

6. Herbst, R. H. Journ. amer. med. assoc. 1912. Nr. 3.

7. Istoman off und Akspianz. Protokoll d. kais. kaukas. med. Gesellschaft. 1. Dez. 1899, Nr. 10.

8. Lenglet. Bull. med. 13. Nov. 1898. Archiv de dermat. et de syphil. 1901. C. 3.

9. Lipschütz. Archiv für Derm. und Syph. 1905. Bd. LXXVI. p. 209, 347. Bd. LXXVII. p. 191, 341.

10. Maréchal. Compt. rend. Soc. de biol. Paris. 52. p. 1115.

11. Majoc chi, D. Soc. ital. di derm. in Rom. 20./XII. 1901.

12. Matzenauer. Lehrbuch der vener. Erkrankungen.

13. Nakano und Takemoto. Japan. Zeitschrift für Derm. und

Syph. 1912. Vol. 12. Fasc. 7.

14. Petersen, O. V. Zentralblatt f. Bakt. u. Par. 1893. Bd. XXIII.

15. Respighi. Soc. ital. di derm. in Rom. 20./XII. 1901.

16. Sow inski. Ref. Monatsh. f. prakt. Derm. 1908. Bd. XLVII.

17. Stein, R. Zentralbl. f. Bakt. I. Abt. Orig. 1908. Bd. XLVI.

18. Tomas czewski. Handb. der Geschlechtskrankheiten. Bd. II.

1912. Zeitschrift f. Hyg. 1903. Bd. XLII. Areh. f. Derm. 1904. Bd. IXXI.

19. Tam u ra. Japan. Zeitschrift. 1912. Vol. 12. Fasc. 7.

1905. $\mathrm{p}_{\text {. }} 753$. 